\title{
Effect of Temperature and Particle Size on the Yield of Bio-oil, Produced from Conventional Coconut Core Pyrolysis
}

\author{
Shirley J. Duarte, Jorge Lin, Dario Alviso, and Juan C. Rolón
}

\begin{abstract}
Thermochemical conversion processes can transform biomass in solid, liquid and gaseous fuels. Among these processes, pyrolysis allows a pyroligneous condensate, similar to fuel oil, called bio-oil. This research focused on conventional pyrolysis of Paraguayan coconut core, in order to determine the effects of temperature and particle size on the bio-oil yield; as well as to obtain physico-chemical properties of the biofuel under the selected operating conditions. Uncondensed gases generated during pyrolysis were analyzed as well as the bio-oil stability in a two month period at $40{ }^{\circ} \mathrm{C}$. The experiments were carried out using an electric oven, a fixed bed reactor and a vertical concentric condenser. The analysis of variance indicated that both factors have a significant influence on performance, and also indicates interactions between them. The liquid properties included water content of $53 \% \mathrm{w} / \mathrm{w}, \mathrm{pH}$ 2.41, kinematic viscosity of $1.51 \mathrm{cSt}$, specific gravity of 1.0739 and higher calorific value between $14.75 \mathrm{MJ} / \mathrm{kg}$ to $10.88 \mathrm{MJ} / \mathrm{kg}$. Uncondensed gases were composed mainly of $\mathrm{CO}$ and $\mathrm{CO}_{2}$ with small amounts of $\mathrm{CH}_{4}$ and $\mathrm{C}_{3} \mathrm{H}_{8}$, which were generated, up to 45 minutes after reaching pyrolysis temperature. Finally, stability tests indicated that bio-oil obtained is stable until the fourth day of storage at $40{ }^{\circ} \mathrm{C}$.
\end{abstract}

Index Terms-Chemical properties, fixed bed reactor, heating rate, stability.

\section{INTRODUCTION}

The growing awareness of the environmental problems that entails the use of fossil fuels, have made that the different governments be heading in the search for alternatives to these fuels. In this context, biofuels, or fuels derived from biomass, arise as an alternative to the use of non-renewable fuels, providing the advantages of reducing greenhouse gas emissions and secure supply of energy products [1].

Biomass comprises a heterogeneous group of organic materials from natural sources (animal or vegetable) or derived from human activities (agro-industrial waste and municipal waste), capable of being transformed into energy, biomaterials or other products of high added value. This is considered one of the greatest sources of renewable energy because its energy content comes from solar energy fixed by plants in photosynthetic processes [2].

Manuscript received April 2, 2015; revised June 10, 2015. This work was supported in part by the Department of Scientific and Technological Research of the National University of Asuncion.

Shirley J. Duarte and Jorge Lin are with the National University of Asuncion, Faculty of Chemical Sciences, Department of Industrial Applications, Paraguay (e-mail: sjoamduart@gmail.com, linyangjorge@hotmail.com).

Dario Alviso and Juan C. Rolón are with the National University of Asuncion, Faculty of Engineering, Department of Mechanical and Energy, Paraguay (e-mail: beto.alviso@gmail.com; jcrolon@ing.una.py).
The use of biomass as an energy alternative has the advantages of being a potential substitute for fossil fuels.

A wide variety of solid, liquid and gaseous fuels can be produced from biomass, and environmental problems related to the disposal of organic waste can be solved. In addition, biomass can increase the profitability of crop processes and does not contribute to increase greenhouse gases, i.e., the net balance of $\mathrm{CO}_{2}$ emissions is zero.

In predominantly agricultural countries, agro-industrial waste is considered as major source of biomass. In Paraguay, according to [3]; between 7 and 10 tons of coconut core and coconut shell per hectare per year is generated as agro-industrial sub products.

Currently, the core and shell coconut are used in boilers for heat generation. However, this method of traditional use is very inefficient because much of the energy is wasted in hot gases exhaust, it remains unburned or vaporized due to fuel moisture [4].

Through pyrolysis process is possible to obtain a liquid fuel with higher value-added, i.e. bio-oil. This fuel is manageable in combustion processes and generates lower toxic emissions compared to those of petroleum fuels. A mixture of combustible gases and carbonaceous solid residue can be used directly as fuel or can be transformed into activated carbon, with a higher value-added product [5].

Bio-oil is a biofuel obtained by condensation of the vapors coming from biomass sources pyrolysis.

Numerous studies such as those conducted by [6] and [7], demonstrate the influence of operational variables in the yield of bio-oil, using coconut core as feedstock. However in Paraguay, as far as we know there has not been conducted yet a detailed research about coconut core processing for the production of bio-oil and activated carbon.

In this paper the influence of pyrolysis temperature and particle size on the yield of bio-oil obtained from coconut core, variety Acrocomia aculeate is studied. Also, for selected operating conditions, the composition of the condensable gases during the reaction and the variations in the properties of the bio-oil obtained in a two months period are analyzed.

\section{Pyrolysis OF COCONUT CORE}

Sundaram \& Natarajan (2009), investigated the influence of pyrolysis temperature, heating rate and grain size in the performance of pyrolysis products [6]. The study was carried out using a fixed bed reactor, at temperatures between $400-600^{\circ} \mathrm{C}$, constant rate of heating of $20^{\circ} \mathrm{C} / \mathrm{min}, 40{ }^{\circ} \mathrm{C} / \mathrm{min}$ and $60{ }^{\circ} \mathrm{C} / \mathrm{min}$ and particle size in the range of 0.15 to 1.80 
$\mathrm{mm}$. They observed that, for a rate of $60^{\circ} \mathrm{C} / \mathrm{min}$, the yield of liquid and gas increased from $38 \%$ to $43 \%$ and $30 \%$ to $33 \%$ respectively when the final pyrolysis temperature of $400{ }^{\circ} \mathrm{C}$ is increased to $600{ }^{\circ} \mathrm{C}$, while the yield of the solid decreases from $32 \%$ to $22 \%$. The yield of liquid and solid increased significantly when increasing particle size. Concerning the heating rate, heating rates low, produce low yields of the liquid, increasing as the rate increases. Furthermore, they observed that the heat capacity of bio-oil obtained was similar to that of Gasoil.

The selected operating conditions encountered in the study are: final pyrolysis temperature of $550{ }^{\circ} \mathrm{C}$, grain size ranging from 1.18 to $1.8 \mathrm{~mm}$ and heating rate of $60{ }^{\circ} \mathrm{C} / \mathrm{min}$. With a maximum liquid yield than $45 \%$.

Joardder et al. (2011), carried out the pyrolysis of coconut core in pirotubular fixed bed reactor, analyzing the effect of bed temperature, particle size and reaction time on the yield of bio-oil [7]. Test were performed in a pyrolysis temperature range of $400-600{ }^{\circ} \mathrm{C}$, particle sizes between 0.6 to $6 \mathrm{~mm}$, reaction times up to $125 \mathrm{~min}$ and flow of inert gas $\left(\mathrm{N}_{2}\right)$ constant at $6 \mathrm{~L} / \mathrm{min}$. The authors concluded that:

1) When the final pyrolysis temperature varies from $400{ }^{\circ} \mathrm{C}$ to $600{ }^{\circ} \mathrm{C}$, the liquid yield initially increased, reaching a maximum value at the temperature of $450{ }^{\circ} \mathrm{C}$, above which the performance returns to decline.

2) Performance liquid decreases with increasing of grain size (unlike studies by [6], in which the performance of bio-oil increases when increasing grain size).

3) For certain conditions, the yield of bio-oil is maximum when the reaction time is $100 \mathrm{~min}$, below this value, the reaction is incomplete and thus the yield is lower, whereas above this value the yield remains almost constant.

4) Best performance was $34.3 \%$ for the operating conditions of: $450{ }^{\circ} \mathrm{C}$ temperature, grain size $0.6 \mathrm{~mm}$, reaction time of $100 \mathrm{~min}$ and nitrogen gas flow of 6 $\mathrm{L} / \mathrm{min}$.

\section{Methodology}

\section{A. Characterization of the Coconut Core}

The coconut core used in this study was obtained from the eastern region of Paraguay (Paraguarí).

Sarubbi (2014), characterized the coconut core, respect to its approximate analysis and higher heating value, according to Mexican Norm B-030, B-036, B-157 and the ASTM D3175 [8]. The results are presented in Table I.

TABLE I: APPROXIMATE ANALYSIS AND Higher HeATING VALUE [8]

\begin{tabular}{|c|c|c|}
\hline Parameter & Value & Unit of measure \\
\hline Ash & 1.75 & $(\% \mathrm{w} / \mathrm{w})$ \\
\hline Volatiles & 75.25 & $(\% \mathrm{w} / \mathrm{w})$ \\
\hline Humidity & 5.1 & $(\% \mathrm{w} / \mathrm{w})$ \\
\hline Fixed carbon & 17.9 & $(\% \mathrm{w} / \mathrm{w})$ \\
\hline Higher heating value & 4604.73 & $(\mathrm{cal} / \mathrm{g})$ \\
\hline
\end{tabular}

\section{B. Experimental Design}

The influence of the independent variables (pyrolysis temperature and particle size) on the dependent variable (performance in bio-oil) was determined.

The selected approach corresponds to factorial design $3^{2}$. Factor A was the pyrolysis temperature in three levels: 450
${ }^{\circ} \mathrm{C}, 500{ }^{\circ} \mathrm{C}$ and $550{ }^{\circ} \mathrm{C}$. Factor B was the particle size in three levels: $2-1.4 \mathrm{~mm} ; 850-600 \mu \mathrm{m} ; 425-300 \mu \mathrm{m}$.

\section{Number of Experiments and Randomization}

The total number of possible combinations of independent variables levels is 9 (three temperature levels multiplied three particle size levels). Experiments were performed three times each; therefore, the total number was 27 . In Table II, are showed the randomized results, using Microsoft Office Excel 2007 Software.

TABLE II: DISTRIBUTING TESTS FOR THE DIFFERENT OPERATING

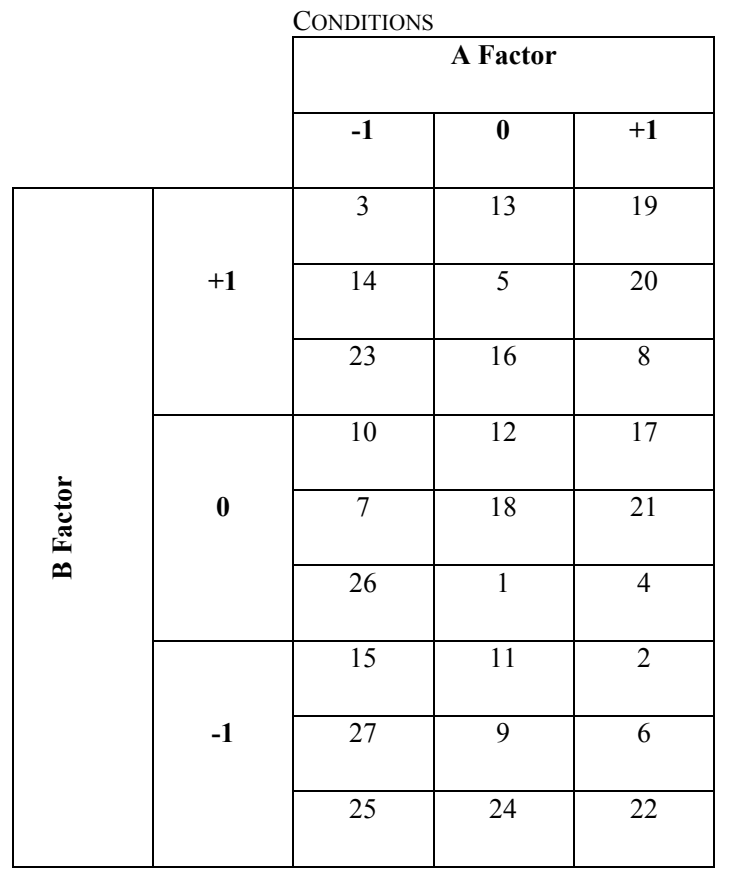

\section{Experimental Procedure}

Fig. 1 presents a diagram of the process.

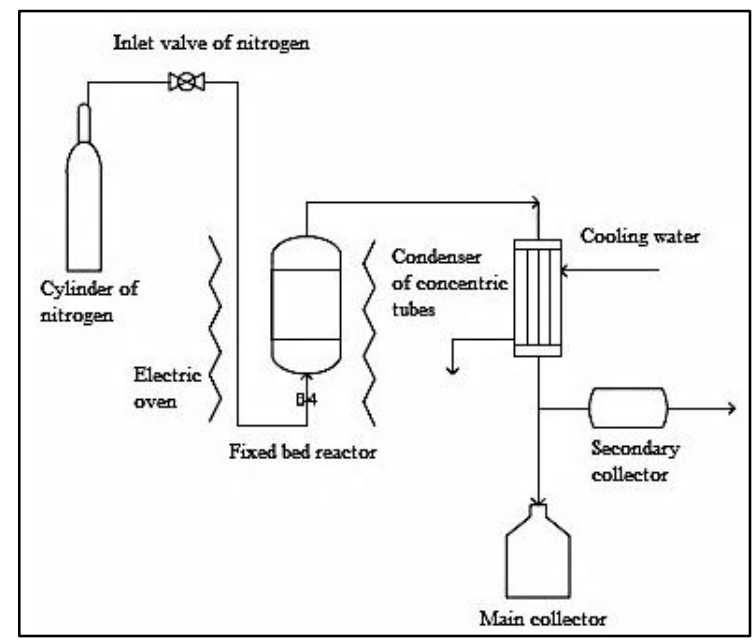

Fig. 1. Process flow diagram.

The set up consists of an electric oven, a nitrogen balloon, a fixed bed reactor, a vertical condenser of concentric tubes and two condensate collectors. The reactor consists of a stainless steel tube AISI 304 of $19 \mathrm{~cm}$ length; $3.81 \mathrm{~cm}$ outer diameter and $3.54 \mathrm{~cm}$ inner diameter; and at the end of it, two segments of wire mesh Tyler No. 300, in order to support the bed. Inside the furnace, the reactor is vertically supported to a 
pipe section of the same material as the reactor, through which nitrogen gas is transported. The condenser consists of two concentric tubes of $3.81 \mathrm{~cm}$ and $2.54 \mathrm{~cm}$ diameter and 30 $\mathrm{cm}$ length. The condensate collector or main collector collects most of the condensate formed in the process. The collector B is located at the exit of the exhaust line of non-condensable gases and its objective is to retain the condensate escaping.

The reactor was charged with $90 \mathrm{~g}$ of coconut core dried at $105^{\circ} \mathrm{C}$ for 24 hours (moisture: $0.74 \% \mathrm{w} / \mathrm{w}$ ). The charge was introduced into the furnace before each experiment. The system purging was performed with nitrogen gas at $2 \mathrm{~L} / \mathrm{min}$ flow rate for a $10 \mathrm{~min}$ period.

The pyrolysis was carried out under a non-linear heating rate, with $16.5^{\circ} \mathrm{C} / \mathrm{min}$ average rate, for a period of $45 \mathrm{~min}$, studying the performance of pyrolytic liquid, as well as the char and that of non-condensable gases, for three particle sizes of coconut core.

During pyrolysis process, nitrogen gas flow was kept constant, performing two functions: to maintain the anaerobic conditions and to flush fluid for the products that are formed by controlling the gases residence time. A similar procedure was made by [7].

\section{E. Pyrolysis Products Yields}

Bio-oil yield: calculated as the percentage of the coconut core mass fraction of the feed that is condensed as bio-oil, using Equation (1).

$$
\eta_{\text {bio-oil }}=\frac{\text { Weight }_{\text {bio-oil }}}{\text { Weight }_{\text {coconut core }}} \times 100
$$

Char yield: calculated as the percentage of the coconut core mass fraction, which is converted to a solid carbonized (char), using Equation (2).

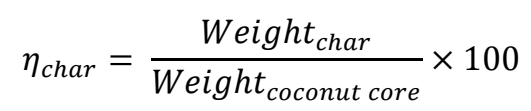

Effluent gases yield: calculated from the mass balance, using Equation (3).

$$
\eta_{\text {bio-oil }}+\eta_{\text {char }}+\eta_{\text {gases }}=100
$$

\section{F. Bio-oil Characterization}

The characterization of bio-oil, obtained using the best conditions established prior by a correlational study, from the variance analysis ANOVA, was conducted.

Higher heating value: it was determined using a calorimeter pump by measuring the increase in temperature of water caused by the combustion of $1 \mathrm{~g}$ sample and using energy balance Equation (4)

where:

$$
H H V=\frac{C_{B} \times \Delta T}{m_{s}}
$$

- $H H V$ : is the higher calorific power.

- $C_{B}$ : is the constant of the calorimetric bomb used.

- $\Delta T$ : is the increase in temperature of the water mass.

- $m_{s}$ : mass of the sample.

Viscosity: it was performed using ASTM D 445 method, designed for measuring kinematic viscosity of liquid petroleum fuels. This method uses an Ostwald viscometer and distilled water as reference liquid. Oasmaa and Peacocke (2001), found that small deviations in temperature causes greater measurement errors in tests conducted at $20^{\circ} \mathrm{C}$, compared to those performed at temperature $40{ }^{\circ} \mathrm{C}$ [9]. Therefore, the latter was selected as the reference temperature for measurement.

Relative density: it was determined by taking standard ASTM D4052 method that uses a Gay-Lussac pycnometer at $25^{\circ} \mathrm{C}$ average temperature of Paraguay.

$\mathrm{pH}$ : it was determined by direct measurement using a pHmeter.

Water content: it was performed using Karl-Fisher method. The analysis was carried out in National Institute of Technology, Standardization and Metrology (INTN-Py).

\section{G. Analysis of Chemical Composition of the Effluent Gases Analysis}

For the analysis of non-condensable gases issuing the pyrolysis process, the operating conditions used were those defined as the most favorable in the ANOVA analysis. An infrared spectrometer coupled to Fourier transform (model DX Gasmet 3000) was used. Once the system reached $100{ }^{\circ} \mathrm{C}$ composition data was collected each 5 minutes, for a period of 45 minutes. The element $\mathrm{H}_{2}$, was not detected due to limitations of the instrument.

\section{H. Stability Study}

The stability study was carried out storing 10 samples of bio-oil in an oven at $40{ }^{\circ} \mathrm{C}$. Each sample consisted of $40 \mathrm{~mL}$ of biofuel, arranged in an Erlenmeyer matrass of $100 \mathrm{~mL}$ with lid and stored for a period of time showed in Table III, after which it was removed and analyzed viscosity and $\mathrm{pH}$ values were analyzed.

Table III shows the storage periods employed for the different samples.

TABLE III: STORAGE PERIODS FOR BIO-OILS SAMPLES
\begin{tabular}{|c|c|c|c|}
\hline $\begin{array}{c}\text { Sample } \\
\text { number }\end{array}$ & $\begin{array}{c}\text { Storage } \\
\text { days }\end{array}$ & $\begin{array}{c}\text { Sample } \\
\text { number }\end{array}$ & $\begin{array}{c}\text { Storage } \\
\text { days }\end{array}$ \\
\hline $\begin{array}{c}\text { Sample 1 } \\
\text { Sample 2 }\end{array}$ & 0 & $\begin{array}{c}\text { Sample 7 } \\
\text { Sample 8 }\end{array}$ & 28 \\
\hline Sample 3 & 4 & $\begin{array}{c}\text { Sample 9 } \\
\text { Sample 10 }\end{array}$ & 42 \\
Sample 4 & 11 & $\begin{array}{c}\text { Sample 11 } \\
\text { Sample 12 }\end{array}$ & 57 \\
\hline Sample 5 & & \multicolumn{2}{|c}{} \\
Sample 6 & 1
\end{tabular}

\section{RESUlTS AND DisCUSSION}

\section{A. Performance in $\% w / w$ for the Mass Fraction of Bio-oil, Char and Non Condensable Gases}

The yields of the different fractions (bio-oil, char, incondensable gases) obtained from the pyrolysis process at different operating conditions are presented in Table IV (A, B and $\mathrm{C}$ ). The measurements have a standard deviation less of 1.65 .

In Table IV A, B and C it is observed that for all possible combinations of factors in each experiment, bio-oil yields were greater than $32 \% \mathrm{w} / \mathrm{w}$. This value is higher than the one obtained by conventional pyrolysis [5].

The char average yield was about $35 \% \mathrm{w} / \mathrm{w}$, which is considered for its usage as briquettes of higher heating value, considering that the calorific power would be between $7500-$ 
$9000 \mathrm{cal} / \mathrm{g}$.

TABLE IV-A: Performance of the DifFERENT Fractions OBTAINED (BIO-OIL) FOR THE DIFFERENT OPERATING CONDITIONS

\begin{tabular}{|c|c|c|c|c|}
\hline & \multirow{3}{*}{ Temperature $\left({ }^{\circ} \mathrm{C}\right)$} & \multirow{2}{*}{\multicolumn{3}{|c|}{$\begin{array}{l}\text { Yields of the differents pyrolysis } \\
\text { products } \\
\text { Bio-Oil }\end{array}$}} \\
\hline & & & & \\
\hline & & 450 & 500 & 550 \\
\hline \multirow{3}{*}{ 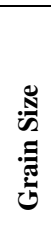 } & $\begin{array}{l}\text { Large } \\
(2 \mathrm{~mm}>\mathrm{p}>1.4 \mathrm{~mm})\end{array}$ & 35.52 & 36.80 & 36.22 \\
\hline & $\begin{array}{l}\text { Medium } \\
(850 \mu \mathrm{m}>\mathrm{p}>600 \mu \mathrm{m})\end{array}$ & 36.23 & 36.54 & 38.17 \\
\hline & $\begin{array}{l}\text { Small } \\
(425 \mu \mathrm{m}>\mathrm{p}>300 \mu \mathrm{m})\end{array}$ & 36.00 & 32.33 & 35.40 \\
\hline
\end{tabular}

TABLE IV-B: PERFORMANCE OF THE DIFFERENT FRACTIONS OBTAINED (CHAR) FOR THE DIFFERENT OPERATING CONDITIONS

\begin{tabular}{|c|c|c|c|c|}
\hline & \multirow{2}{*}{. } & \multicolumn{3}{|c|}{$\begin{array}{l}\text { Yields of the differents pyrolysis } \\
\text { products }\end{array}$} \\
\hline & & \multicolumn{3}{|l|}{ Char } \\
\hline & Temperature $\left({ }^{\circ} \mathbf{C}\right)$ & 450 & 500 & 550 \\
\hline \multirow{3}{*}{ 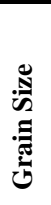 } & $\begin{array}{l}\text { Large } \\
(2 \mathrm{~mm}>\mathrm{p}>1.4 \mathrm{~mm})\end{array}$ & 36.50 & 35.53 & 34.09 \\
\hline & $\begin{array}{l}\text { Medium } \\
(850 \mu \mathrm{m}>\mathrm{p}>600 \mu \mathrm{m})\end{array}$ & 36.85 & 35.73 & 34.17 \\
\hline & $\begin{array}{l}\text { Small } \\
(425 \mu \mathrm{m}>\mathrm{p}>300 \mu \mathrm{m})\end{array}$ & 36.43 & 35.23 & 33.63 \\
\hline
\end{tabular}

TABLE IV-C: PERFORMANCE OF THE DIFFERENT FRACTIONS OBTAINED (INCONDENSABLE GASES) FOR THE DIFFERENT OPERATING CONDITIONS

\begin{tabular}{|c|c|c|c|c|}
\hline & \multicolumn{3}{|c|}{$\begin{array}{l}\text { Yields of the differents pyrolysis } \\
\text { products }\end{array}$} \\
\hline & & \multicolumn{3}{|c|}{ Incondensable gases } \\
\hline & Temperature $\left({ }^{\circ} \mathbf{C}\right)$ & 450 & 500 & 550 \\
\hline \multirow{3}{*}{ 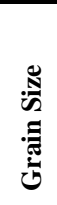 } & $\begin{array}{l}\text { Large } \\
(2 \mathrm{~mm}>p>1.4 \mathrm{~mm})\end{array}$ & 27.98 & 27.68 & 29.68 \\
\hline & $\begin{array}{l}\text { Medium } \\
(850 \mu \mathrm{m}>\mathrm{p}>600 \mu \mathrm{m})\end{array}$ & 26.92 & 27.73 & 27.66 \\
\hline & $\begin{array}{l}\text { Small } \\
(425 \mu \mathrm{m}>\mathrm{p}>300 \mu \mathrm{m})\end{array}$ & 26.82 & 32.44 & 30.72 \\
\hline
\end{tabular}

The non-condensable gases mass fractions issuing the process are non negligible due to its chemical composition, rich in $\mathrm{CO}, \mathrm{CO}_{2} ; \mathrm{H}_{2}$ and $\mathrm{CH}_{4}$. It can be used in others process of chemical conversion.

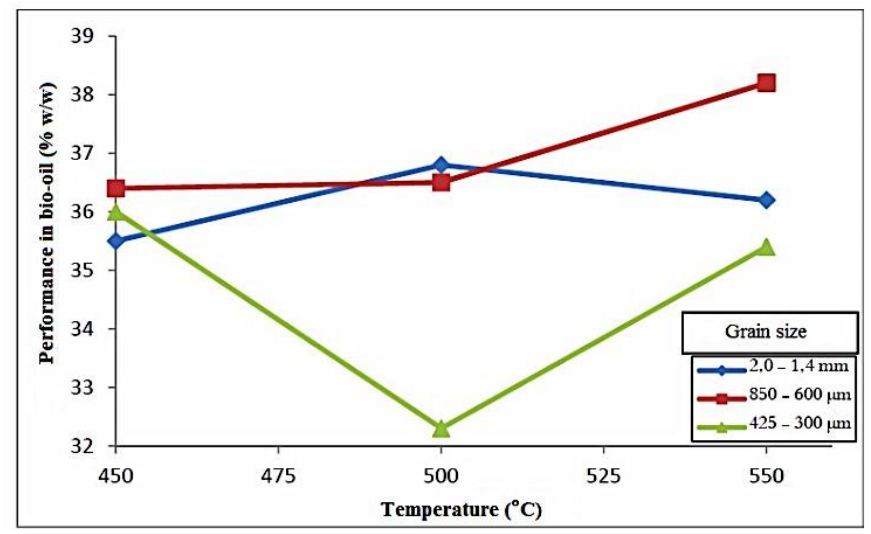

Fig. 2. Yield average in Bio-oil for different combination of temperature and grain size.

\section{B. Influence of Temperature and Particle Size in Bio-oil Performance}

Fig. 2 shows the yield average as function of the pyrolysis temperature and the grain size levels.

A preliminary analysis suggests that higher yields are obtained at $550{ }^{\circ} \mathrm{C}$, whereas a tendency for the effect of grain size on yield is not observed. The existence of interaction between factors is also observed, resulting in nonparallel yield curves.

\section{Statistical Analysis of the Differences in Yield Obtained}

The ANOVA analysis reveals whether the observed differences are significant, or are due to random errors during the experiments and also if there are interactions between the factors. The ANOVA analyses of two factors, carried out using Microsoft Office Excel 2007 software, are presented in Table V.

TABLE V: ANALYSIS OF VARIANCE RESULTS

\begin{tabular}{|l|l|l|l|l|l|}
\hline $\begin{array}{l}\text { Origin of } \\
\text { variations }\end{array}$ & $\begin{array}{l}\text { Sum of } \\
\text { squares }\end{array}$ & $\begin{array}{l}\text { Degrees } \\
\text { of } \\
\text { freedom }\end{array}$ & $\begin{array}{l}\text { Medium } \\
\text { of the } \\
\text { squares }\end{array}$ & $\mathbf{F}$ & $\begin{array}{l}\text { Critical } \\
\text { value } \\
\text { for F }\end{array}$ \\
\hline Grain size & 28.1261 & 2.0000 & 14.0630 & 18.6085 & 3.5546 \\
\hline Temperature & 8.4924 & 2.0000 & 4.2462 & 5.6187 & 3.5546 \\
\hline Interaction & 23.0557 & 4.0000 & 5.7639 & 7.6270 & 2.9277 \\
\hline $\begin{array}{l}\text { Inside the } \\
\text { group }\end{array}$ & 13.6032 & 18.0000 & 0.7557 & & \\
\hline Total & 73.277355 & 26 & & & \\
\hline
\end{tabular}

In Table $\mathrm{V}$ is observed that for grain size and temperature factors, the value calculated for the $\mathrm{F}$ test exceeds the critical value, which indicates that within 5\% error; the observed differences in performance Bio-oil due to each the factors are significant.

It is also noted that the interactions between the variables are significant, which corroborates what was observed in Fig. 2.

As the results of variance analysis indicates that the observed differences are significant we selected the operating conditions, corresponding to a grain size between 850-600 $\mu \mathrm{m}$; and pyrolysis temperature of $550{ }^{\circ} \mathrm{C}$.

\section{Physicochemical Characterization of Bio-oil Obtained Using the Best Conditions}

The results of the physical-chemical characterization are presented for the Bio-oil obtained at $550{ }^{\circ} \mathrm{C}$ and with a grain size between $850-600 \mu \mathrm{m}$.

\section{1) Organoleptic analysis}

The bio-oil obtained has a dark brown color, with a sour smell, similar to that of smoke.

Initially two phases were present, the upper phase (about $20 \%$ volume with slightly cloudy color) and the lower phase (with a darker appearance). Phase separation is indicative that water content in bio-oil is high, generally more than $30-35 \%$. However, after 2-3 hours there was spontaneous mixture of both phases, showing slight micelles (deep black) within the liquid.

Centrifugation tests, were performed at $5000 \mathrm{rpm}$ for a period of 15 minutes, however, no clear phase separation was observed. Therefore, the physicochemical properties were determined to the mixture previously homogenized.

\section{2) Physico-chemical properties}

The results of the physicochemical characterization of the bio-oil are summarized in Table VI. 
TABLE VI: PHYSICO-CHEMICAL PROPERTIES OF BIO-OIL OBTAINED BY CONVENTIONAL PYROLYSIS OF THE COCONUT CORE OF THE VARIETY

\begin{tabular}{|c|c|c|}
\multicolumn{2}{|c|}{ ACROCOMIA ACULEATA } \\
\hline $\begin{array}{c}\text { Kinematics viscosity } \\
\text { at } 40{ }^{\circ} \mathrm{C}\end{array}$ & Results & Unit of measure \\
\hline $\mathrm{pH}$ & 1.51 & $\mathrm{cSt}$ \\
\hline $\mathrm{HHV}$ pure bio-oil & $14.75-10.88$ & $\mathrm{MJ} / \mathrm{kg}$ \\
\hline $\begin{array}{c}\mathrm{HHV} \text { bio-oil }+ \\
\text { methanol }\end{array}$ & $14.58 \pm 0.83$ & $\mathrm{MJ} / \mathrm{kg}$ \\
\hline $\begin{array}{c}\text { Relative density at } \\
25^{\circ} \mathrm{C}\end{array}$ & $1.0739 \pm 0.0005$ & - \\
\hline
\end{tabular}

In Table VII, the properties of water content, viscosity and density are presented. Experiments were conducted at the National Institute of Technology, Standardization and Metrology (INTN).

TABLE VII: PHYSICO-CHEMICAL PROPERTIES OF BIO-OIL OBTAINED REALIZED BY THE INTN

\begin{tabular}{|c|c|c|}
\hline Analysis & Results & Unit of measure \\
\hline $\begin{array}{c}\text { Kinematics viscosity } \\
\text { at } 40{ }^{\circ} \mathrm{C}\end{array}$ & 1.64 & $\mathrm{cSt}$ \\
\hline Water content & 53 & $\mathrm{~g} / \mathrm{mL}$ \\
\hline Density at $25^{\circ} \mathrm{C}$ & 1.06993 & \\
\hline
\end{tabular}

As it can be observed, moisture content is very high compared to typical values of bio-oil samples, whose values varies in the range of $15-30 \%$ [10].

Considering that moisture from biomass used was $0.74 \%$, the high water content would suggest the presence of secondary reactions of dehydration between the pyrolysis products. This assumption is supported by the presence of a carbonaceous residue in the pipeline that connects the reactor with the condenser, immediately at the furnace exit. The solid could be due to condensation and dehydration of bio-oil in this region, due to lack of insulation.

The high water content directly affects the other properties analyzed. In the case of viscosity, the bio-oil obtained has a fluid consistency, with a kinematic viscosity slightly higher than twice that of water value at the same temperature, which is lower compared to values presented by [10] who proposed typical viscosity values of bio-oil in the range of 10-100 cSt at $40{ }^{\circ} \mathrm{C}$.

There are differences between the viscosity obtained in the laboratories of the Chemistry Faculty at the UNA and the one determined by the INTN. This discrepancy might be due to the reactions of bio-oil aging, since the tests at INTN were realized on the fourth day of its obtainment.

The $\mathrm{pH}$ measurement obtained is in agreement with the expected values for samples of bio-oil, due to its high content of volatile acids [9]. However, it is expected that the presence of high water content increase the corrosive properties, especially at elevated temperatures [10].

Concerning the higher heating value, numerous tests were performed to determine this property, however, the high moisture content produces poor combustion, resulting in a large dispersion between the values obtained. In fact, in most of the tests, combustion of bio-oil did not occur. To overcome this problem, we add $10 \%$ (volume) of methanol in the bio-oil, with a significant improvement in the combustion process.

The results indicate that, despite the high water contents; the higher calorific value of bio-oil is comparable to typical values for samples from other biomass sources [10]. However, it was lower than the one reported by [11], who conducted the pyrolysis of coconut core of India obtaining values of $19.75 \mathrm{MJ} / \mathrm{kg}$ in samples of bio-oil with $10 \%$ humidity. However, the reported density values are similar to those obtained in the present study.

\section{3) Comparison between the physicochemical properties of} the bio-oil and the fuel oil

The Ministry of Industry and Trade, through resolution 1336/2013 establishes the technical specifications for the Fuel Oil commercialized in Paraguay. Comparing the properties of bio-oil obtained with these specifications can observe the following:

- The higher calorific value of bio-oil is considerably lower than the fuel oil, equaling at approximately $36.3 \%$ of the energy released by the fuel oil during the combustion of the same amount of mass.

1) Therefore, in order to get the same amount of energy, it is necessary to use a greater volume of bio-oil.

2) The bio-oil is less viscous, with the kinematic viscosity (measured at $40{ }^{\circ} \mathrm{C}$ ) approximately 463 times lower than Fuel Oil. This is favorable, since the low viscosity is beneficial for pumping and injection processes, thereby avoiding the need for prior heating, such as for the fuel oil.

3) Given the low pH of the bio-oil, the same will be much more corrosive than fuel oil, which implies that for the handling and usage is required corrosion resistant materials.

\section{E. Chemical Analysis of Non-condensable Gases}

In Fig. 3, is observed the results of chemical analysis of the incondensable gases generated in the pyrolysis conventional process of the coconut core, variety Acrocomia aculeata. These results were obtained using a final temperature of pyrolysis of $550{ }^{\circ} \mathrm{C}$, particle size between $850 \mu \mathrm{m}$ and $600 \mu \mathrm{m}$; and a heating rate average equal to $16.5^{\circ} \mathrm{C} / \mathrm{min}$.

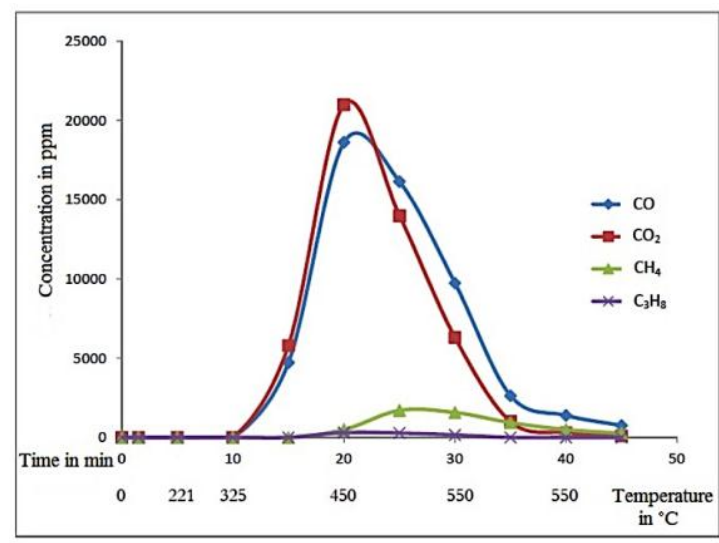

Fig. 3. Chemical analysis the incondensable gases generated in the pyrolysis conventional process.

During the process is expected that the release of hydrogen gas would occur at temperatures near $500{ }^{\circ} \mathrm{C}$ by breaking $\mathrm{C}-\mathrm{H}$ bond and the formation of $\mathrm{H}-\mathrm{H}$ bond, according to [12] and [13]. However, it was not possible to verify this due to limitations of the instrument used.

The results indicate that the major gaseous products of conventional pyrolysis of coconut core are $\mathrm{CO}_{2}$ and $\mathrm{CO}$, whereas $\mathrm{CH}_{4}$ and $\mathrm{C}_{3} \mathrm{H}_{8}$ are produced only in trace amounts. 
This is in agreement with the results obtained by [12].

Ethylene and propane gases were present at very low concentrations compared to other major components. Traces of $\mathrm{NO}$ and $\mathrm{NO}_{2}$ were also detected and the presence of Acetylene and $\mathrm{N}_{2} \mathrm{O}$ was discarded.

Fig. 3 shows that the formation of gas begins after ten minutes of the heating process. $\mathrm{CO}$ and $\mathrm{CO}_{2}$ are the first species formed during the process. At that moment the furnace temperature was approximately $300{ }^{\circ} \mathrm{C}$ and the gases formed probably due to the onset of decomposition of hemicellulose described by [14].

The formation of $\mathrm{CO}$ and $\mathrm{CO}_{2}$ reaches a maximum peak at 20 minutes, when the oven temperature is $450{ }^{\circ} \mathrm{C}$. This is in agreement with values presented by [13]. The $\mathrm{CO}_{2}$ is produced mainly of cracking and reforming of the carboxyl groups, present mainly in the hemicellulose. While CO formation would have two sources: first, the carbonyl and carboxyl cracking in cellulose and hemicellulose groups, and second, the secondary reactions between the generated volatiles.

\section{F. Stability or Aging Study}

The stability study was performed for the bio-oil obtained to a pyrolysis temperature of $550{ }^{\circ} \mathrm{C}$ and particle size between $860 \mu \mathrm{m}$ and $600 \mu \mathrm{m}$.

\section{1) Longitudinal analysis of the variation of $\mathrm{pH}$}

The results of measuring the $\mathrm{pH}$ of the stored samples are showed in Fig. 4.

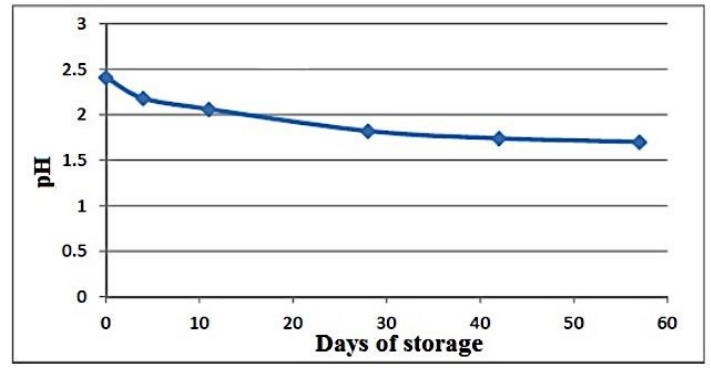

Fig. 4. PH evolution of bio-oil samples stored at $40{ }^{\circ} \mathrm{C}$.

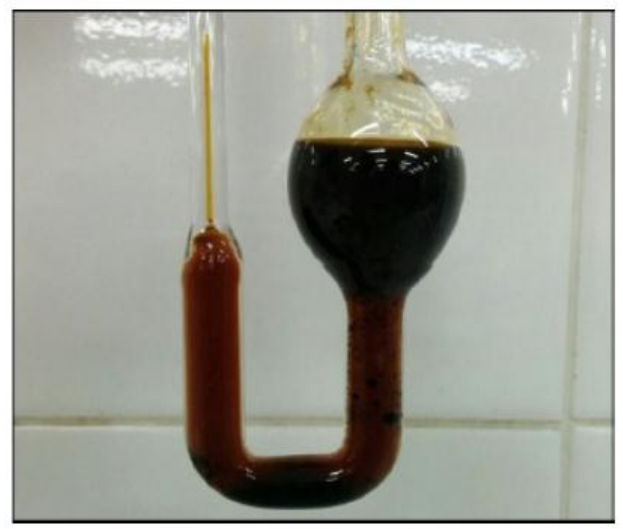

Fig. 5. Phase separation in the bio-oil, after 11 days storage at $40{ }^{\circ} \mathrm{C}$.

It can be observed that the largest decrease in $\mathrm{pH}$ occurs in the first month of storage, from 2.41 (day 0) to 1.82 (day 28), while in the second month only a slight decrease is observed up to day 42, after which it remains almost constant. This could suggest that the main reactions that cause the instability of bio-oil are given during the first month of storage.

The decrease of $\mathrm{pH}$ may be due to increased concentration of carboxylic acids, product of the oxidation reactions of alcohols and aldehydes described by [15].

\section{2) Longitudinal analysis of the variation of the kinematic viscosity}

Concerning the kinematic viscosity, the samples analyzed on the fourth day of storage showed an increase of approximately $10 \%$ of its initial value $(1.51 \mathrm{cSt}$ to $1.67 \mathrm{cSt})$. However, on the eleventh day of storage phase, separation of the samples was found (see Fig. 5), which prevented for following days the determination of this property by Ostwald viscometer.

In order to analyze the viscosity of bio-oil samples having phase separation, Lu et al. (2009) recommends the use of rotational viscometers [10]. However, given the low viscosity of bio-oil obtained, is required a minimum of $200 \mathrm{~mL}$ to obtain reliable results. This amount was not available when conducting the analysis.

According to [15], the viscosity increase is due to polymerization reactions between the compounds present in the bio-oil, while phase separation could be due to advanced polymerization reactions, esterification reactions that transformed the carboxylic acids of polar character, to esters of character non polar and dehydration reactions, which increase the water content and causes the destabilization of the emulsion. Yu et al. (2007) studied the aging of bio-oil samples obtained from corn crop residue [16]. The bio-oil obtained had a moisture level of $15.2 \%$ and phase separation occurred after 30 days of storage, also at $40{ }^{\circ} \mathrm{C}$. Stabilization tests conducted by adding methanol and ethanol, concludes that the phase separation was inhibited, with a minimum $10 \%$ methanol (by volume).

\section{G. Additional Stability Tests of Methanol/Bio-oil Mixtures $10 \% \mathrm{v} / \mathrm{v}$ and $20 \% \mathrm{v} / \mathrm{v}$}

Additional tests were performed with the addition of $10 \%$ v/v and $20 \%$ v/v methanol to bio-oil samples and $80{ }^{\circ} \mathrm{C}$ for 48 hours storage. Phase separation was also observed in the samples, however, is noted that the separation was less pronounced with increasing percentage of methanol.

Finally, an addition of approximately $30-40 \%$ methanol was tested. In this case no phase separation was observed after three months storage at room temperature.

\section{CONCLUSION}

The results of analysis of variance (ANOVA) indicate, with $95 \%$ confidence that the variables pyrolysis temperature and grain size significantly affect performance in bio-oil.

The findings suggest the presence of interactions between the study variables, observable by plotting the average response for each combination of treatments in which the yield curves versus temperature were not parallel for the different grain sizes studied. This result was compared by ANOVA.

Best performance in bio-oil was approximately $38 \%$ using the pyrolysis temperature of $550{ }^{\circ} \mathrm{C}$ and grain size comprised between 850 and 600 microns.

The bio-oil, showed a water content significantly higher 
than desired, which affects the other properties analyzed. The main affected properties were viscosity and higher calorific value, both below reference levels. Also, the bio-oil showed a very lean combustion condition considerably improved by the addition of $10 \%$ methanol.

The higher heating value of the bio-oil was variable, presenting a range of values between $14.75 \mathrm{MJ} / \mathrm{kg}$ to 10.88 $\mathrm{MJ} / \mathrm{kg}$.

The higher heating value of the bio-oil / methanol mixture was on average $14.58 \mathrm{MJ} / \mathrm{kg}$.

It was observed that, at equal amount of mass, the higher calorific value of bio-oil equivalent to $36 \%$ of fuel oil, value which totals $40 \%$ if the comparison is done per unit volume. While the viscosity turned out approximately 463 times lower.

Storage of bio-oil has the disadvantage of phase separation and the low $\mathrm{pH}$ forces the use of materials resistant to corrosion, such as stainless steel or corrosion resistant polymers.

The condensable gases were composed mainly of $\mathrm{CO}$ and $\mathrm{CO}_{2}$ with low amounts of methane and propane, until after 45 minutes of heating.

\section{REFERENCES}

[1] A. Friedmann and R. Penner, Biocombustibles, alternativa de negociosverdes, Asunción: USAID, 2009.

[2] J. Fernández, Energía de la Biomasa: La energía en sus claves, Madrid, FundaciónIberdrola, pp. 397-445, 2004.

[3] E. Bohn, Tablero de comandopara la promoción de biocombustibles en Paraguay, Santiago de Chile: ONU. 2008, p. 110.

[4] G. A. Gaffert, "Centrales de vapor: Estudio de la construcción, característicasdelfuncionamiento e integración de toda la maquinariapesada y ligera de una central," Reverté, 1981.

[5] A. V. Bridgwater and S. A. Bridge, "A review of biomass pyrolysis and pyrolysis technologiesIn Biomass pyrolysis liquids upgrading and utilization," Springer Netherlands, pp. 11-92, 1991.

[6] E. G. Sundaram and E. Natarajan, "Pyrolysis of coconut shell: An experimental investigation," Journal of Engineering Research, vol. 6, no. 2, pp. 33-39, 2009.

[7] M. U. H. Joardder, M. R. Islam, M. Beg, and R. Alam, "Pyrolysis of coconut shell for bio-oil," in Proc. International Conference on Mechanical Engineering (ICME2011), Dhaka, Bangladesh, ICME11-ABS-037, Dec. 2011.

[8] M. B. Sarubbi, "Producción y caracterización de carbónactivado, en un reactor de lechofijo, a partir de carozo de coco -Acrocomiaaculeata- del Paraguay," Bachelor grade dissertation, Universidad Nacional de Asuncion, Asuncion, 2014.

[9] A. Oasmaa and C. Peacocke, A Guide to Physical Property Characterisation of Biomass-derived fast Pyrolysis Liquids, Espoo: Technical Research Centre of Finland, 2001.

[10] Q. Lu, W. Z. Li, and X. F. Zhu, "Overview of fuel properties of biomass fast pyrolysis oils," Energy Conversion and Management, vol. 50, no. 5, pp. 1376- 1383, 2009.

[11] K. Tanmaya, "Pyrolysis of coconut shell," M.Sc. Dissertation, NIT Rourkela, India, 2013.

[12] T. Siengchum, M. Isenberg, and S. S. Chuang, "Fast pyrolysis of coconut biomass-an FTIR study," Fuel, vol. 105, pp. 559-565, 2013.

[13] H. Yang, R. Yan, H. Chen, D. H. Lee, and C. Zheng, "Characteristics of hemicellulose, cellulose and lignin pyrolysis," Fuel, vol. 86, no. 12, pp. 1781-1788, 2007.

[14] K. Raveendran, A. Ganesh, and K. C. Khilar, "Pyrolysis characteristics of biomass and biomass components," Fuel, vol. 75, no. 8, pp. 987-998, 1996.

[15] J. P. Diebold, "A review of the chemical and physical mechanisms of the storage stability of fast pyrolysis bio-oils," National Renewable Energy Laboratory, NREL/SR-570-27613, Colorado, USA, pp. 59, Jan, 2000

[16] F. Yu, S. Deng, P. Chen, Y. Liu, Y. Wan, A. Olson, and R. Ruan, "Physical and chemical properties of bio-oils from microwave pyrolysis of corn stover," Applied Biochemistry and Biotecnology, pp. 957-970, Humana Press, 2007.

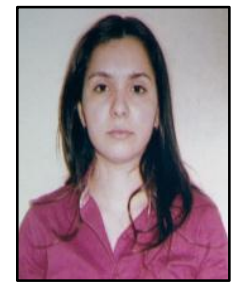

Shirley J. Duarte earned her chemical engineering degree in 2010 and her master in science from the National University of Asunción (UNA), Paraguay. Presently she is pursuing a Ph.D. degree in the field of pyrolysis and gasification of agroindustrial waste biomass in the Chemical Engineering Department, Centrale Supélec, Francia. She is a teacher assistant of chemical engineering at Chemistry Faculty, National University of Asunción (UNA). She has 4 years experience on teaching and research assistance. Her areas of interest are renewable energy and environmental engineering, reaction engineering, modeling and simulation.

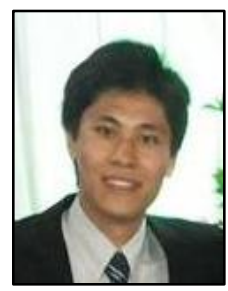

Jorge Lin Yang earned his chemical engineering degree in 2014 from the National University of Asunción (UNA), Paraguay. His current interests lies in biofuels, especially those from the pyrolysis and gasification process. He also has interest in others sources of renewable energy, such as solar energy and wind power. He has worked in several research projects. His degree work was focused on conventional pyrolysis of coconut shell.

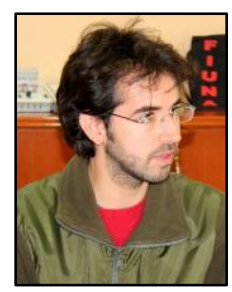

Dario Alviso earned his electro-mechanical engineering degree in 2007 from the National University of Asuncion (UNA), his master of science in energy from the Ecole Centrale Paris (ECP) in 2008 and his $\mathrm{PhD}$ from both ECP and UNA (cooperation) in 2013. He is an assistant professor of Fluid Mechanics and Combustion at the UNA since 2013. His PhD work was entitled Experimental and numerical studies of biodiesel combustion in a counterflow burner. Experimentally, his current interests lies in flame spectroscopy, radical imaging, laser induced fluorescence and laser Doppler velocimetry. Numerically, his interests lies in the modeling of renewable fuels, such as biodiesel and ethanol, and the simulation of these fuels flames in a 1D and OD configurations. He has published several papers in both journal and conferences in Europe, USA and South-America.

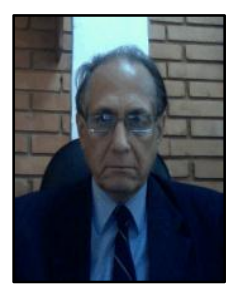

Juan Carlos Rolón has been on the teaching staff of Ecole Centrale Paris since 1982 as an assistant Professor, and has been a Professor at that institution since 1989. He is teaching fluid mechanics, combustion, signal processing, control systems and optical diagnostics. He earned his master of science in theoretical physics from the University of Moscow in 1970, his DEA in Fluid Mechanics from University of Paris 6 in 1973 and his PhD from Ecole Centrale Paris in 1988. He was successively research engineer at Ecole Centrale Paris from 1973 to 1975 , then invited research scientist at CNRS during two years. Before his return to Ecole Centrale he was a Professor in Physics at the Ecole Normale Supérieure in Oran (Algeria) from 1976 to 1982. Professor Rolon leads a research team in the area of flame structures and optical diagnostics. His current interests lie in flame spectroscopy, radical imaging, combinations of imaging and digital processing, light scattering, laser induced fluorescence, laser Doppler velocimetry and Particle Image Velocimetry. He has published more than eighty papers on these various topics and he has participated with invited talks in prestigious conferences as the Gordon Research Conferences. His research has been supported by governmental agencies and by companies and he was the principal investigator of three European contracts. The European Office of Research and Development recently selected him as invited professor and leading speaker of a Window on Science program at the AFRL Wright-Patterson Laboratory (Dayton). He was invited conferee in different international scientific events, as the Gordon research Conference (2001), the International Symposium on Combustion and Atmospheric Pollution", 2003 St Petersburg and the NAL (National Aerospace Laboratory) of Japan (2003). The French Academy of Sciences awarded him with the higher scientific level, the Grand Prix 1997. He is also co-worker with Dr. D. Thevenin and P. H. Rennard for the 1997 First Award from the Seymour Cray competitions on numerical simulation and intensive computing. In recognition of his academic investment and work, the Government decorated Professor Juan Carlos Rolon with the order of Chevalier de Palmes Academiques, and in 2010 he was promoted by the the Government to the grade of Officer of Palmes Academiques. Since 2008 he returned to Paraguay and become Research Professor at the Universidad Nacional de Asunción. In 2012 he received the Academic Degree of Doctor Honoris Causa, Universidad Nacional de Asunción. 